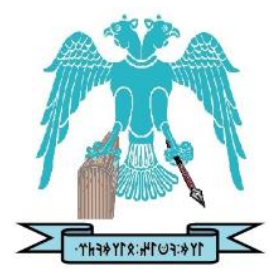

JOURNAL OF ENERGY SYSTEMS

$2021,5(2)$

\title{
Structural design and testing of pouch cells
}

\author{
Aluru Vamsi \\ Structural Engineering Entity, Vikram Sarabhai Space Centre, Trivandrum, Kerala, India, \\ aluruvamsi3000@gmail.com \\ Jamal Nawaz Ansari \\ Vikram Sarabhai Space Centre, Trivandrum, Kerala, India, Jamalnawaz786@gmail.com \\ Sundaresan Malli Krishnamoorthy \\ Structural Engineering Entity, Vikram Sarabhai Space Centre, Trivandrum, Kerala, India, \\ mksundaresan15@gmail.com \\ Chitaranjan Pany ${ }^{(D)}$ \\ Structural Engineering Entity, Vikram Sarabhai Space Centre, Trivandrum, Kerala, India, \\ c_pany@yahoo.com \\ Bibin John ${ }^{(D)}$ \\ Vikram Sarabhai Space Centre, Trivandrum, Kerala, India, bbnjohn@gmail.com \\ Aiswarya Samridh \\ Vikram Sarabhai Space Centre, Trivandrum, Kerala, India, aiswaryasamridh@yahoo.com
}

Mercy Thelakkattil Devassia (D)

Vikram Sarabhai Space Centre, Trivandrum, Kerala, India, mercytd@gmail.com

$\begin{aligned} \text { Submitted: } & 25.11 .2020 \\ \text { Accepted: } & 01.03 .2021 \\ \text { Published: } & 30.06 .2021\end{aligned}$

Abstract: A reliable supply of energy source is required for aerospace applications. Due to their high specific energy density and low self-discharge, Lithium-ion cells are preferred over other energy sources. Pouch cells have much better energy density compared to metallic cell cases. A pouch cell is developed for launch vehicle and automotive applications. Two aluminum-polymer laminates are heat sealed at $180-1900{ }^{\circ} \mathrm{C}$ to form the pouch cell. Experimental characterization ( lap shear, T-peel and tensile) of bonded laminate/films are carried out. UTS of laminate is obtained from lap shear and tensile tests. Fracture energy (mode-1) is obtained from T-peel tests and used as an input for the cohesive zone model. Mechanics of pouch cell due to internal pressure (abuse condition) is performed by Elasto-plastic finite element structural analysis to arrive at the pressure capacity of cells.

Keywords: $\quad$ Aluminum-polymer laminates, Burst test, Experiment, Finite element analysis, Pouch cell

$\begin{array}{ll}\text { Vamsi, A., Ansari, J.N., Krishnamoorthy S.M., Pany, C., John, B., Samridh, A., Devassia, M.T., } \\ \text { Cite this paper as: } & \text { Structural design and testing of pouch cells. Journal of Energy Systems, 2021,5(2), 80-91, DOI: }\end{array}$ $10.30521 /$ jes. 815160

(c) 2021 Published by peer-reviewed open access scientific journal, JES at DergiPark (https://dergipark.org.tr/en/pub/jes)

\begin{tabular}{r|l} 
Nomenclature & \\
\hline $\mathrm{b}$ & Width of the peel test specimen \\
CZL & Cohesive zone layer \\
CZM & Cohesive zone modeling \\
$\mathrm{G}$ & Fracture energy per unit area \\
$\mathrm{Pf}$ & Peel force \\
$\mathrm{Us}$ & Strain energy of the system \\
USE & Surface energy \\
$\mathrm{W}$ & Work potential \\
\hline \hline
\end{tabular}




\section{INTRODUCTION}

A battery pack is a system of multiple components and functions. The design involves the application of knowledge and practice in the electrochemical, electrical, mechanical, thermodynamic, and control fields. To achieve higher operating voltages, the positive terminal of one cell is connected to the negative terminal of the next cell in a series combination. Like-polarity terminals of adjacent cells connected to each other in parallel can achieve higher operating power. Cell packaging designs and their combinations in modules and battery packs are offered in a huge variety, for primary and secondary batteries, and for different applications [1-4]. The most critical performance metrics for a Lithium-ion battery pack are energy density, power density, cost, cycle life, and safety. The deviation of the performance metric from the target value is termed as a quality loss. Elimination of the factors responsible for this quality loss is too difficult, expensive, or time consuming. An alternate solution for minimizing this deviation is through robust design methodology [5]. The most popular options available in market are cylindrical and prismatic cells. These types have both goodness and shortcoming. In 1995 [6], Li-polymer surprised the battery world with a radical new design, the pouch cell. Generally, a pouch battery can apply for every application. The pouch cell achieves a 90 to 95 percent packaging efficiency and makes the most efficient use of space, the highest among battery packs, with advantages of flexible size, and safety performance. It reduces weight by eliminating the metal enclosure, however, the cell needs some alternative support in the battery compartment. Further, it reduces cost, as well as optimize packaging efficiency at the battery level. The pouch pack finds applications in consumer, military, automotive applications as well as aerospace application.

Delamination or fracture along an interface between multi-layers material plays a major role in limiting the toughness and the ductility, such as in laminated composite structure and laminated pouch (Aluminum film sandwiched between two polymer layers). This has motivated considerable research on the failure of the interfaces. Interface delamination can be modeled by adopting softening relationships between tractions and the separations, which in turn introduce critical fracture energy, which is the energy, required to break apart the interface surfaces. This is called the cohesive zone material (CZM) model. The interface surfaces of the materials can be modeled by a particular set of interface elements or contact elements, and a CZM model can be used to characterize the constitutive behavior of the interface. The CZM model consists of a constitutive relation between the traction acting on the interface and the corresponding interfacial separation.

In this paper, $1.5 \mathrm{Ah}$ pouch cells are developed in-house for launch vehicle and automotive applications. In pouch cells, the electrode stack and electrolyte are enclosed in a laminated pouch. The pouch is made of the Aluminum film sandwiched between two polymer layers: Polypropylene on the inner side and polyamide on the outer side. The total thickness of the film/laminate is approx. $110 \mu \mathrm{m}$. The pouch is then heat-sealed at $180-190^{\circ} \mathrm{C}$. Laminated pouches are used to contain the active materials and improve the energy density of the cell (as metallic cases are avoided). The maximum effective operating pressure of the pouch cell is 2 bar and in case of cell abuse condition, pressure increases in the cell and causes bursting of cell. This pressure capacity of the cell needs to be estimated prior to usage. Lap shear, t-peel, and tensile tests are studied on bonded Aluminum laminates to obtain the mechanical properties required for structural analysis. Finite element analysis (FEA) and hydro tests are carried out to estimate the capacity of the pouch cell.

\section{MATERIAL CHARACTERISATION}

Four sets of lap shear samples and two sets of peel testing (t-peel) samples were tested as per ASTM D 3163 and ASTM D 1876 respectively. The test setup with specimens is shown in Fig. 1. Details of test 
specimens are given in Table 1. In lap shear test, four types of specimens are tested: i) heat sealed (lap area $=625 \mathrm{~mm}^{2}, 25 \mathrm{~mm}$ width, and 25mm length): L01-L05 (specimen ID) ii) heat sealed (lap area = $250 \mathrm{~mm}^{2}, 25 \mathrm{~mm}$ width, and 10mm length): L06-L10 iii) heat-sealed with tabs (electrodes) in the longitudinal direction (tabs are along with the load): L11-L15 and iv) heat-sealed with tabs in transverse direction: L16-L20.

Results of lap shear tests are given in Table 2. All lap-shear specimens (with and without tab) failed in the laminated sheet indicating robust heat sealing (cohesive fracture in a lap shear test indicates good process control) of pouch cell. From these tests, the tensile strength of the laminated sheet is estimated and values are given in Table 2.

In the t-peel test, two types of specimens are tested, i.e., heat-sealed with and without tabs. The results of t-peel tests are given in Table 3. The following observations are made from tests:

- Presence of tab reduces the peel load of specimens.

- Fracture energy per unit area of the surfaces, $G$, is estimated from the peel load values as follows. In a peel test, total potential energy of the system is:

$$
\Pi=U_{S}+U_{S E}-W
$$

Where, $U_{S}$ is strain energy of the system (sum of elastic and bending energy), $U_{S E}$ is surface energy

$$
U_{S E}=G(\Delta c b)
$$

By using Fig. 2, one can write $W$ as,

$$
W=P f \Delta c(1-\cos \theta)
$$

If the lamination is considered inextensible, then minimization of potential energy is stated as,

$$
\left(\frac{\mathrm{d} \Pi}{\mathrm{d}(\Delta \mathrm{c})}\right)=0
$$

Here, Eq. (4) gives,

$$
G_{b}=P_{f}(1-\cos \theta) \text { i.e. } G=\left(P_{f} / b\right)(1-\cos \theta)
$$

Eq. (5) is known as the Rivlin's equation [7]. Whereas, in Kendall's equation [8], $U_{S}$ term is included. Note that $P_{f}$ and b are peel force and the width of the peel test specimen, respectively. T peel test is performed at $\theta=90^{\circ}$. Fracture energy per unit area $(G)$ values are found out from tests presented in Fig. 1. Average value is found to be of $G=2.33 \mathrm{~N} / \mathrm{mm}$. 


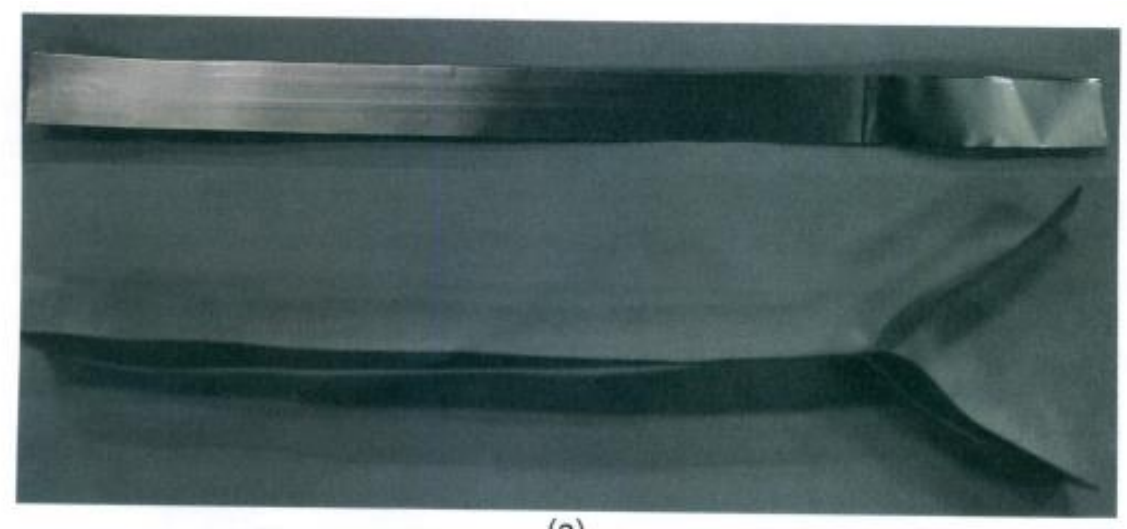

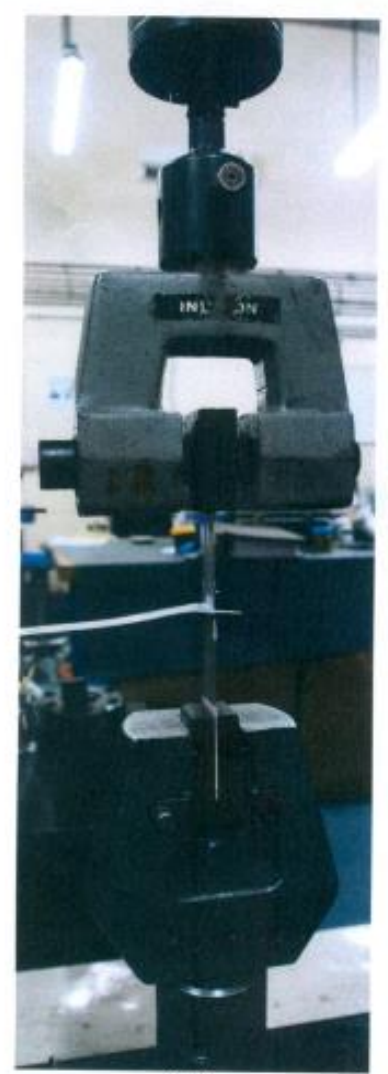

(b) (a)

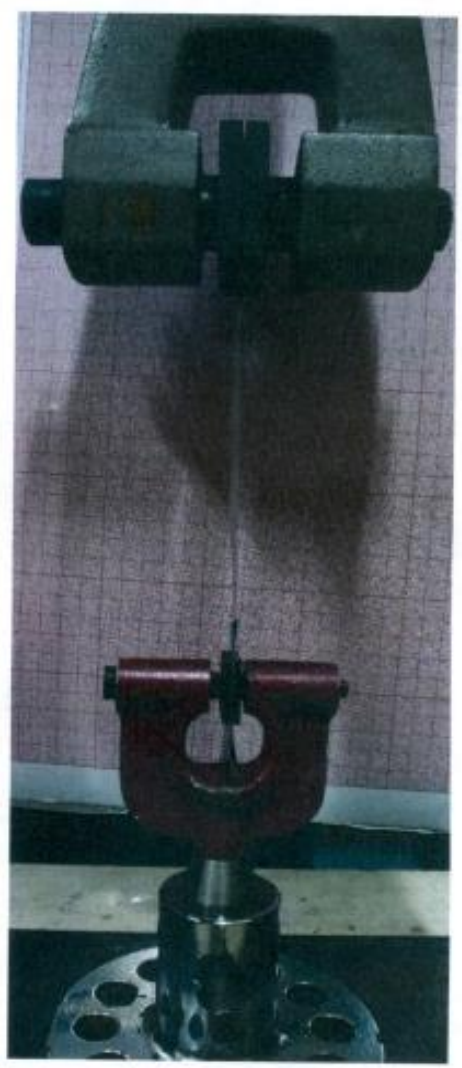

(c)

Figure 1. (a) T-peel specimen, (b) T-peel test setup and (c) Lap shear test setup

Table 1. Details of test specimens.

\begin{tabular}{|c|c|c|c|c|c|}
\hline $\begin{array}{c}\text { Type of } \\
\text { test }\end{array}$ & $\begin{array}{l}\text { Specimen } \\
\text { ID } \\
\end{array}$ & $\begin{array}{l}\text { Number of } \\
\text { specimens }\end{array}$ & Bond detail & $\begin{array}{c}\text { Lap area } \\
\text { (width } x \text { length) }\end{array}$ & Specimen size \\
\hline \multirow{4}{*}{$\begin{array}{l}\text { Lap shear } \\
\text { test }\end{array}$} & L01-L05 & 5 & Heat sealed & $25 \times 25$ & \multirow{4}{*}{$\begin{array}{l}25 \mathrm{~mm} \text { width } \mathrm{x} \\
150 \mathrm{~mm} \text { length }\end{array}$} \\
\hline & L06-L10 & 5 & Heat sealed & $25 \times 10$ & \\
\hline & L11-L15 & 5 & $\begin{array}{l}\text { Heat sealed with tab in } \\
\text { longitudinal direction of } \\
\text { load }\end{array}$ & $25 \times 25$ & \\
\hline & L16-L20 & 5 & $\begin{array}{l}\text { Heat sealed with tab in } \\
\text { transverse direction of load }\end{array}$ & $25 \times 25$ & \\
\hline Peel test & P01-P05 & 5 & Heat sealed & -- & $25 \mathrm{~mm}$ width $\mathrm{x}$ \\
\hline (T peel) & P06-P10 & 5 & Heat sealed with tab & -- & 340mm length \\
\hline
\end{tabular}


Table 1. Results of lap shear test.

\begin{tabular}{|c|c|c|c|c|c|}
\hline $\begin{array}{l}\text { Lap area size (wid. } \\
\text { x leng. } x \text { thk.) } \\
(\mathrm{mm}) \\
\end{array}$ & Condition & $\begin{array}{l}\text { Spec. } \\
\text { ID }\end{array}$ & $\begin{array}{c}\operatorname{Max} . \\
\operatorname{load}(\mathrm{N})\end{array}$ & Location of failure & $\begin{array}{l}\text { Tensile } \\
\text { strength } \\
(\mathrm{MPa})\end{array}$ \\
\hline \multirow{4}{*}{$25 \times 25 \times 0.125$} & \multirow{4}{*}{ Heat sealed } & L01 & 174 & Laminated sheet & 55.68 \\
\hline & & L02 & 181 & away from bond & 57.92 \\
\hline & & L03 & 196 & Laminated sheet & 62.72 \\
\hline & & L04 & 197 & near to bond & 63.04 \\
\hline \multirow{5}{*}{$25 \times 10 \times 0.125$} & \multirow{5}{*}{ Heat sealed } & L06 & 195 & $\begin{array}{l}\text { Laminated sheet } \\
\text { near to bond }\end{array}$ & 62.40 \\
\hline & & L07 & 179 & $\begin{array}{l}\text { Laminated sheet } \\
\text { away from bond }\end{array}$ & 57.28 \\
\hline & & L08 & 203 & & 64.96 \\
\hline & & L09 & 191 & Laminated sheet & 61.12 \\
\hline & & L10 & 184 & & 58.88 \\
\hline \multirow{5}{*}{$25 \times 25 \times 0.125$} & \multirow{5}{*}{$\begin{array}{l}\text { Heat sealed with tab in } \\
\text { longitudinal direction of } \\
\text { load }\end{array}$} & L11 & 195 & & 62.40 \\
\hline & & L12 & 190 & & 60.80 \\
\hline & & L13 & 188 & Laminated sheet & 60.16 \\
\hline & & L14 & 197 & & 63.04 \\
\hline & & L15 & 186 & & 59.52 \\
\hline \multirow{5}{*}{$25 \times 25 \times 0.125$} & \multirow{5}{*}{$\begin{array}{l}\text { Heat sealed with tab in } \\
\text { transverse direction of load }\end{array}$} & L16 & 183 & Laminated sheet & 58.56 \\
\hline & & L17 & 180 & away from bond & 57.60 \\
\hline & & L18 & 173 & $\begin{array}{l}\text { Laminated sheet } \\
\text { near to bond }\end{array}$ & 55.36 \\
\hline & & L19 & 183 & Laminated sheet & 58.56 \\
\hline & & L20 & 189 & away from bond & 60.48 \\
\hline
\end{tabular}

Table 2. Results of t-peel test.

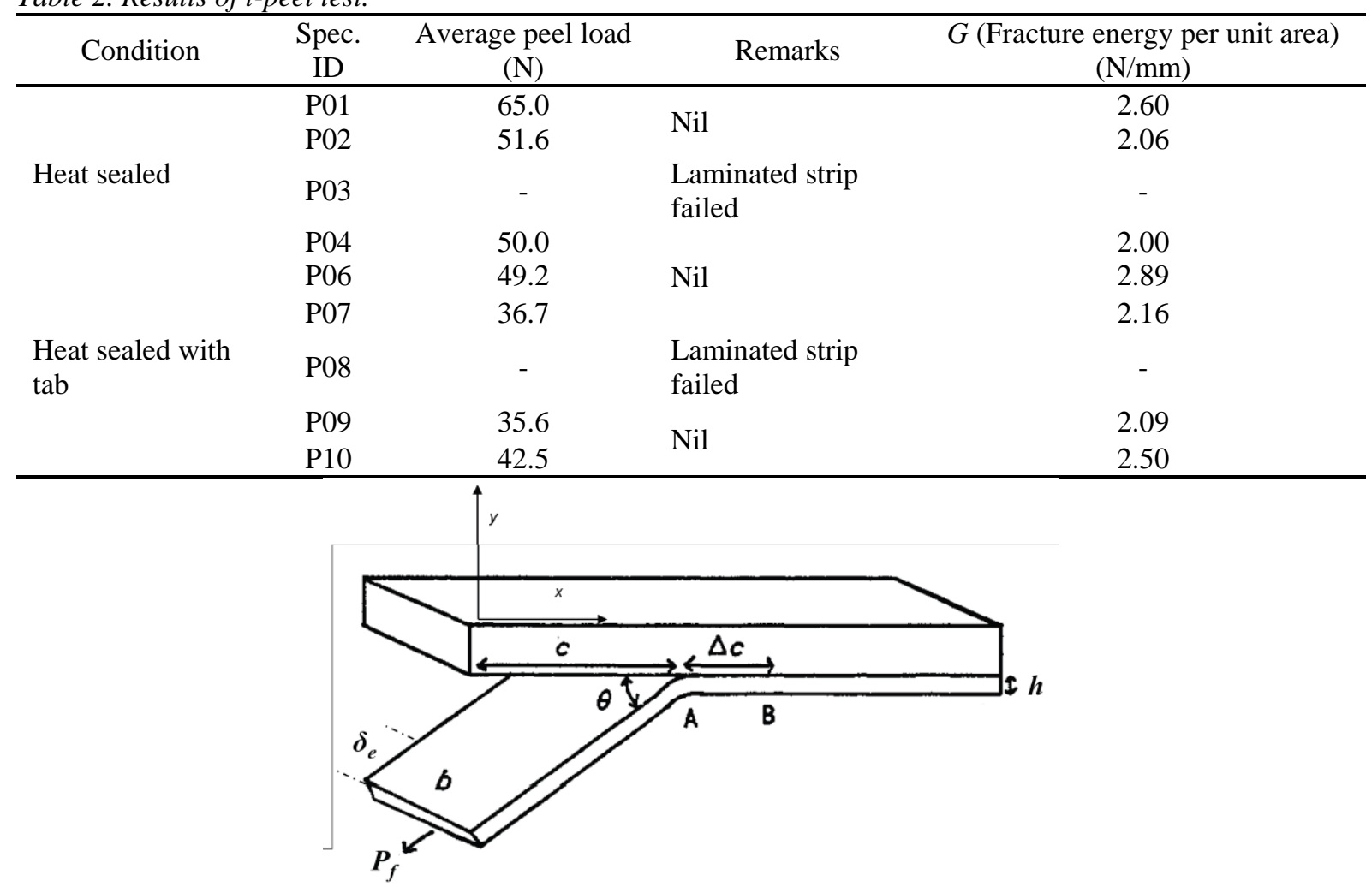

Figure 2. Schematic of peel test for an extensible tape [9]. 
Tensile tests are performed on five specimens from S1 to S5 (as in Figure 1) and material curve of S1 (strength is low) is input for FE analysis. Tensile strength from lap shear tests and tensile tests are close to each other.

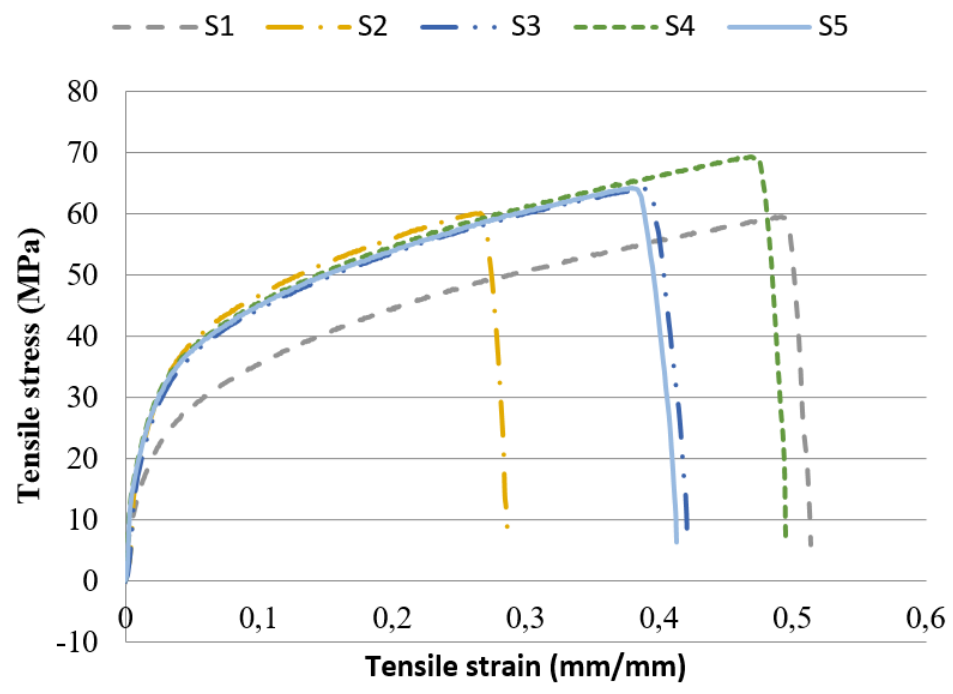

Figure 1. Tensile test data

\section{COHESIVE ZONE LAW (CZL) FOR FEA}

Theory of elasticity predicts stress singularity at the edge of crack tip. The global energy balance equations of Rivlin and Kendall do not dwell into the local behavior of the bonded interface. That is, they cannot estimate the forces and displacements at the interface. One method is to use a CZL, a constitutive law in the form of a traction-separation law, to model the mechanics of process zone (ahead of the crack tip).

From the peel test, $G$ is obtained. This is quantitatively the area under the traction-separation curve. The CZL used for FEA is shown in Figure 2.

$$
\begin{gathered}
(1 / 2) \sigma_{o} \delta_{\mathrm{f}}=\mathrm{G} \\
\sigma_{\mathrm{o}} \delta_{\mathrm{f}}=2 \mathrm{G}=4.66
\end{gathered}
$$

Values of $\sigma_{\mathrm{o}}$ and $\delta_{\mathrm{f}}$ are unknown. Procedure to extract CZL is described by Christopher [10]. For FEA, $\delta_{\mathrm{f}}$ is assumed as 0.4 , then $\sigma_{\mathrm{o}}=\left(4.66 / \delta_{\mathrm{f}}\right)=11.65 \mathrm{MPa}$. $\left[\delta_{\mathrm{o}}=0.1\right]$ 


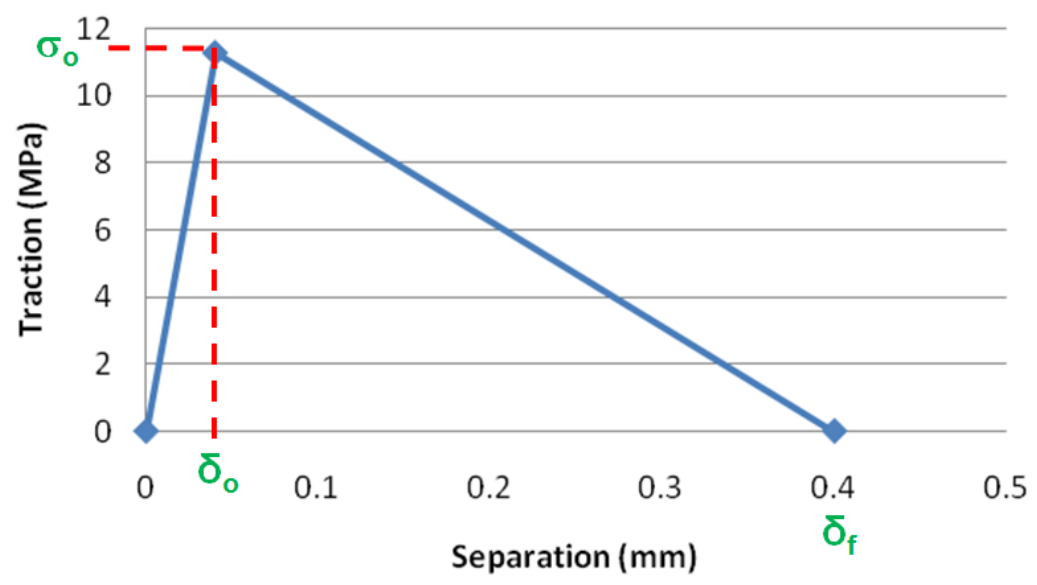

Figure 2. Cohesive zone law for FEA

\section{FEA AND RESULTS}

Finite element model of the laminated pouch is shown in Fig. 5. The quarter model ( $36.25 \times 45.5)$ has been considered because of the symmetric loading conditions. The boundary conditions and internal pressure of 2 bar are shown in Fig. 5. The boundary conditions are for an assembled cell condition. As the stiffness of the stack of the adjacent cells is high, the normal degree of freedom is constrained. Combined geometric \& material (material stress - strain curve is shown in Fig. 6) nonlinear analysis has been performed. Symmetric boundary conditions are applied on the symmetric plane and closed - end condition is simulated on the free edge on the vertical surface. The cohesive zone materials (CZM) is used with interface elements and contact elements allow exponential CZM for simulating interface delamination and fracture phenomena, which is explained in previous section. The parameters $\mathrm{C}_{1}, \mathrm{C}_{2}$ and $\mathrm{C}_{3}$ are supplied for Ansys simulation, which correspond to $\sigma_{\mathrm{o}}, \delta_{\mathrm{f}}$ and $\delta_{\mathrm{o}}$.

The maximum deformation of $1.61 \mathrm{~mm}$ (Fig. 7) is observed in the pouch cup. Max. von - Mises stress at 2 bar is $50.47 \mathrm{MPa}$ and plastic strain is 0.44 and is shown in Fig. 8 and Fig. 9 respectively. These stresses and strains are very local and are due to the sharp corner at the edges of the pouch. A fillet radius will reduce these peaks and stresses and strains show a high gradient from this corner and reduce drastically. From the tensile test data, ultimate strength is 60 to $70 \mathrm{MPa}$ and the ultimate strain is 0.4 to 0.5 . Hence, the pouch cell is safe at 2 bar.

The axial deformation at the interface of the pouch to cover is shown in Fig. 10. The separation at 1st node is 0.0637 , which is greater than $0.04 \mathrm{~mm}$, while at 2 nd node separation is less than $0.04 \mathrm{~mm}$. Thus, debonding at the interface has started at 2 bar pressure and a further increase in pressure may cause further debond. Ting Miao et al., [11] predicted the delamination behavior of arterial wall through four types of CZMs. They could predict the tearing propagation behavior in the medial layer of the arterial tissue. Similar approach has been followed by Bonifaz [12] to simulate the crack tip opening displacement (CTOD). Zhang et al. [13] utilised the concept of CZM to investigate dynamic failure process in homogeneous and functionally graded materials (FGMs).

Failure is expected to take place when the stress in the cell through the thickness is equal or more than the ultimate tensile strength of the material. ANSYS has the provision for checking the global plastic deformation i.e. where non-convergence in solution occurred [14]. It shows the pressure level for complete plastic flow through the cylinder wall (i.e. bursting pressure). The pressure capacity of the pouch cell is estimated to be 6.4 bar. The deformation, plastic strain and effective stress in the cell are shown in Fig. 11, Fig. 12, and Fig. 13, respectively. A considerable increase in the plastic strain is observed when the pressure has increased from 2 bar to 6.4 bar (which is evident from the material curve 
of Fig. 6). At the interface, debonding of $2 \mathrm{~mm}$ is expected to occur, but $8 \mathrm{~mm}$ bond length is still intact as observed from the deformation values at the interface. However, burst tests are needed to validate the analysis results.
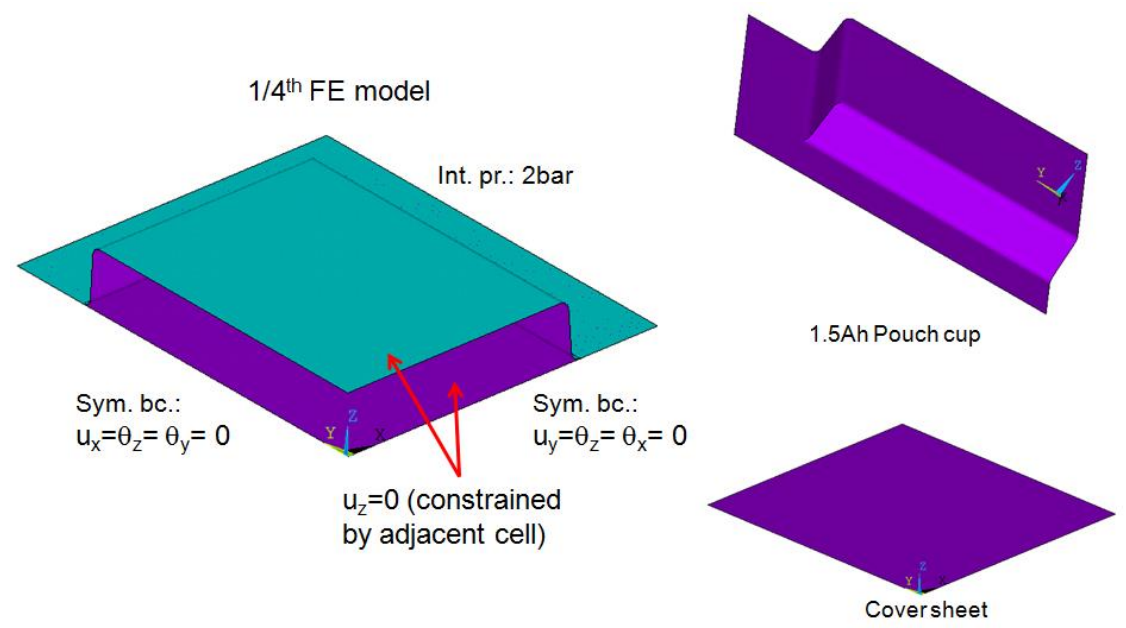

Figure 3. Finite element model (Quarter model laminate).

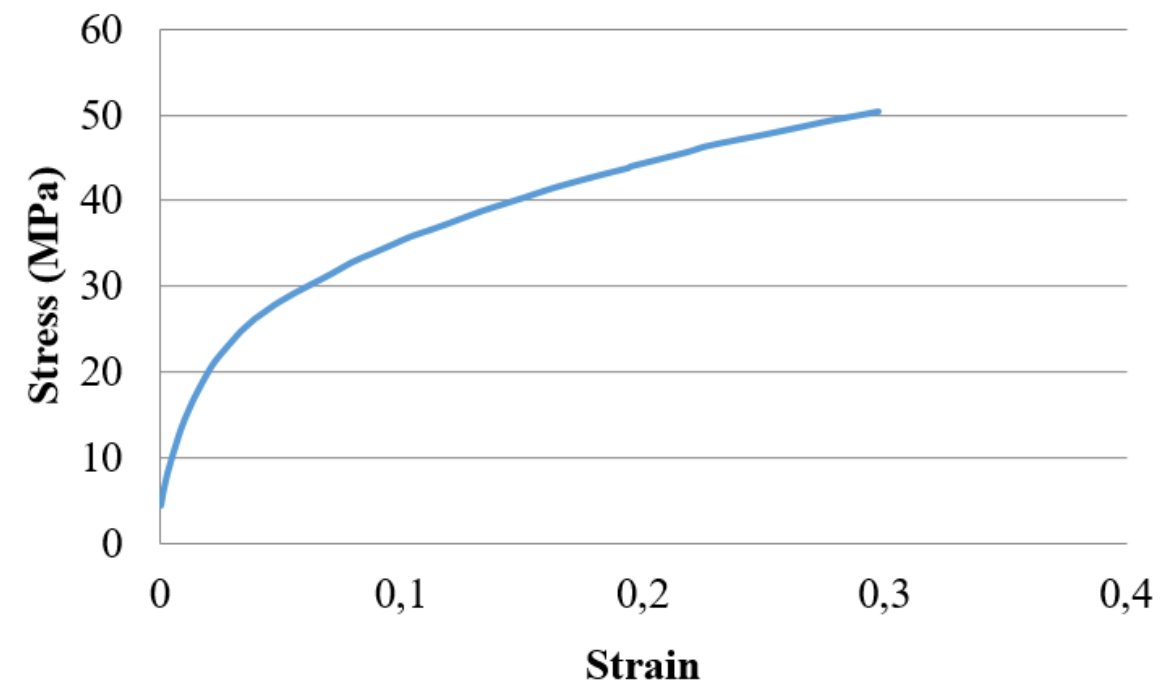

Figure 6. Material stress-strain curve of laminate 


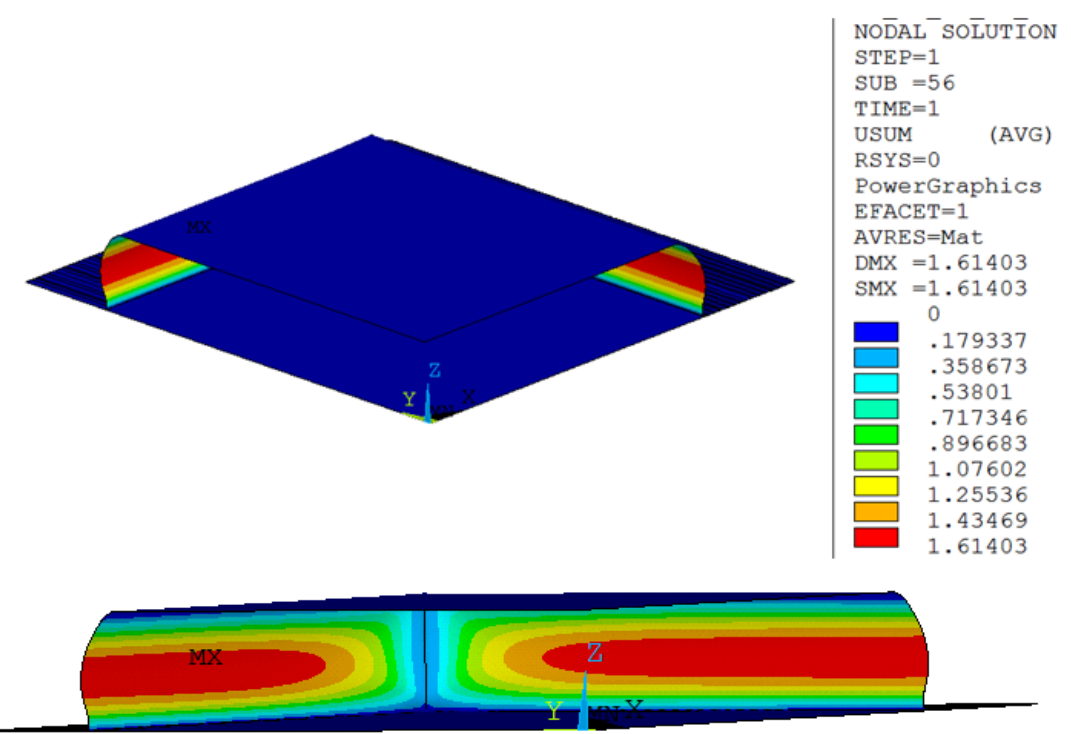

Figure 7. Deformed configuration at 2 bar internal pressure

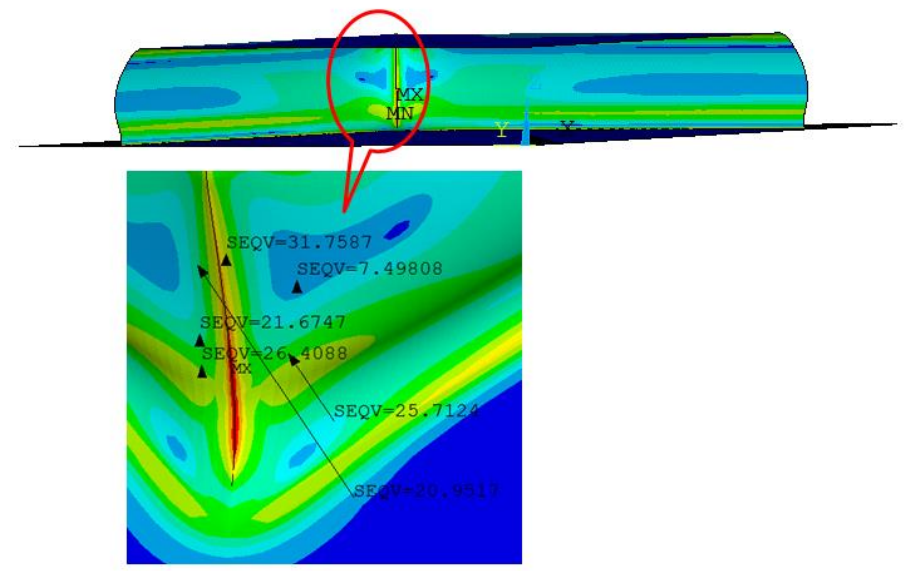

$$
\begin{aligned}
& \begin{array}{l}
T I M E=1 \\
S E Q V
\end{array} \\
& \text { PowerGraphics } \\
& \mathrm{EFACET}=1 \\
& \text { AVRES }=\text { Mat } \\
& \text { DMX }=1.61403 \\
& \text { SMN }=.419 \mathrm{E}-03 \\
& \text { SMX }=50.4759 \\
& .419 \mathrm{E}-03 \\
& 5.6088 \\
& 11.2172 \\
& 16.8256 \\
& 22.434 \\
& 28.0423 \\
& 33.6507 \\
& 39.2591 \\
& 44.8675 \\
& 50.4759
\end{aligned}
$$

Figure 8. Von-mises stress (MPa) in the pouch cup at 2 bar
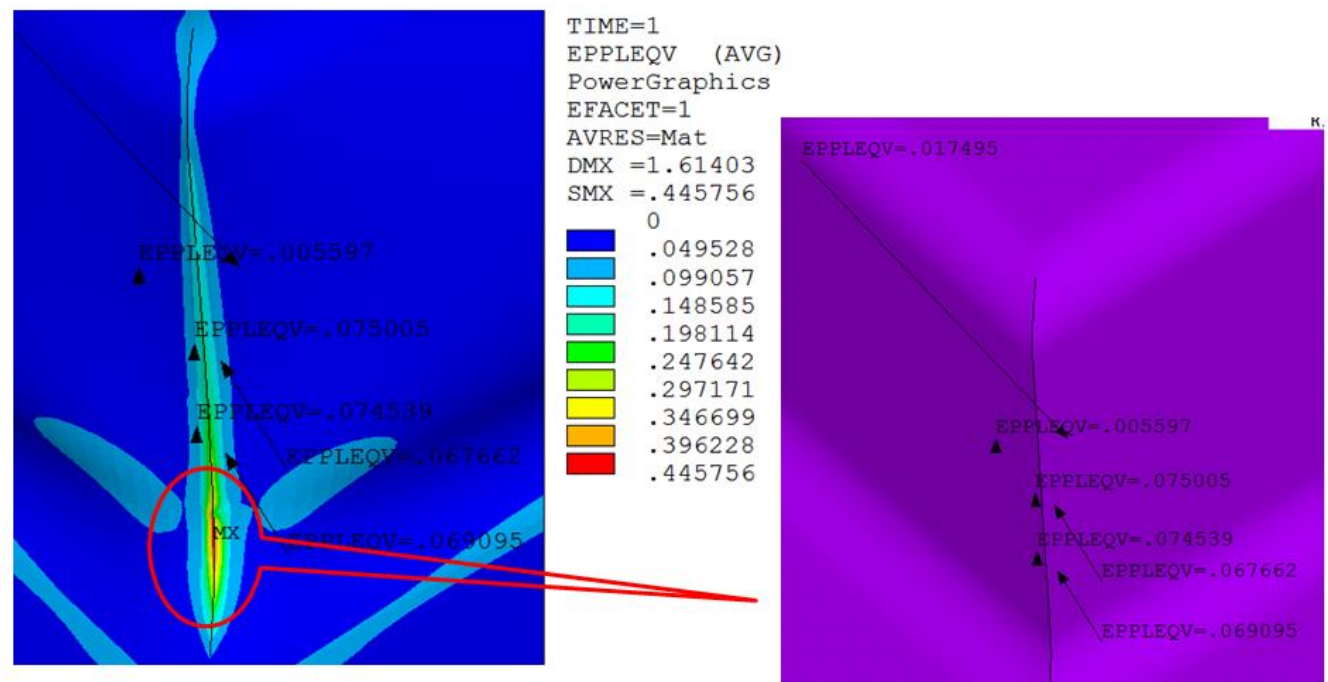

Figure 9. Plastic strain in the pouch cup at 2 bar 


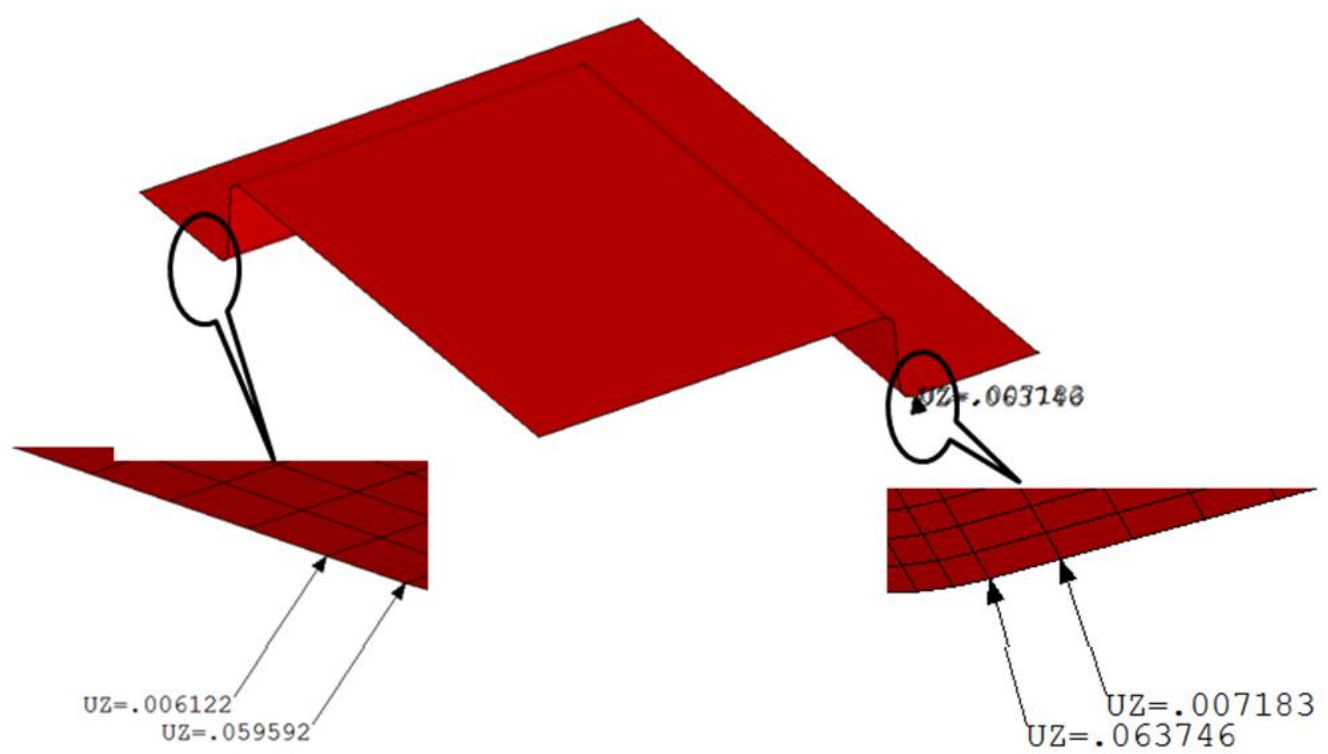

Figure 10. Axial deformation (indicating delamination in cohesive elements) at 2 bar

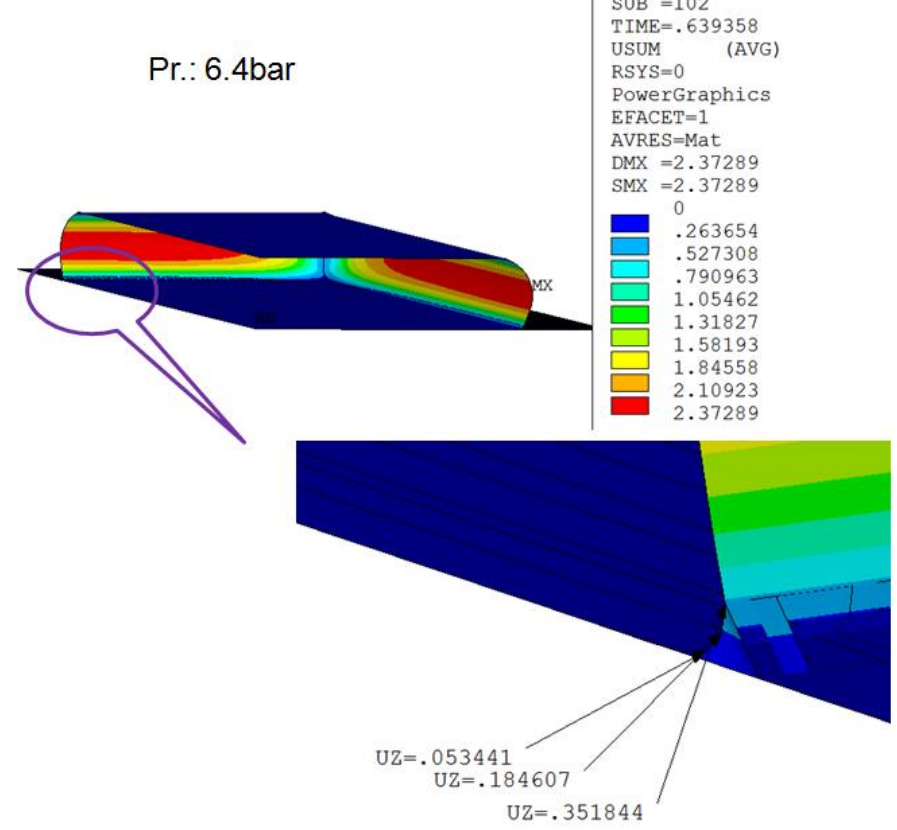

Figure 4. Deformed configuration (Usum) at 6.4 bar internal pressure

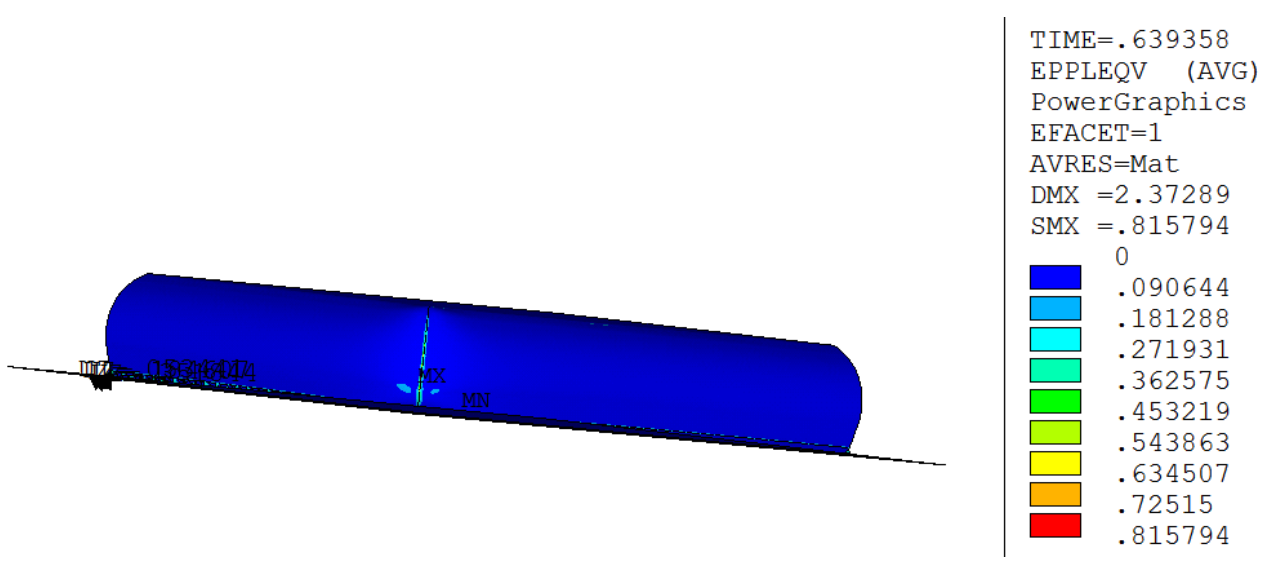

Figure 5. Plastic strain in the pouch cup at 6.4 bar internal pressure 


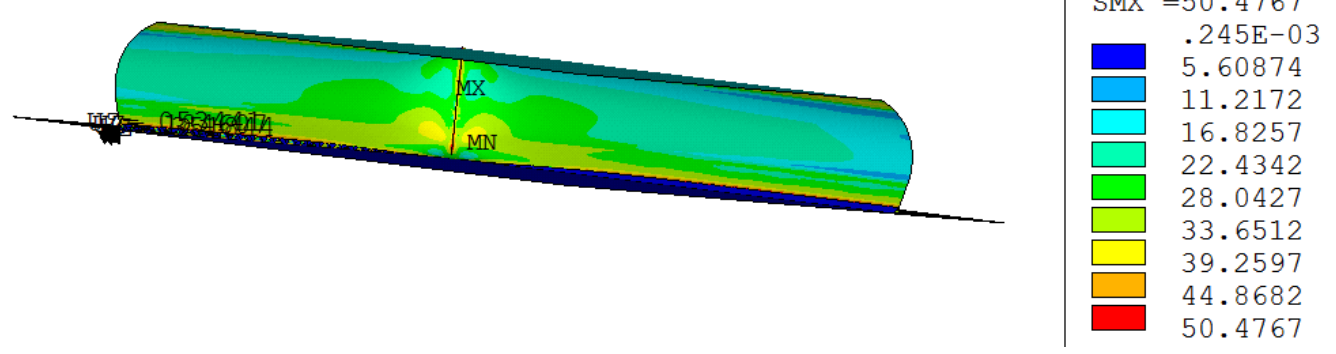

Figure 6. Von-mises stress (MPa) in the pouch cup at 6.4 bar internal pressure

\section{BURST TEST OF POUCH CELL}

The faces of cell cases are restrained in the normal direction as shown in Fig. 14. The cell is internally pressurized with water and 3 number's of cell case is burst tested and the mode of failure observed is delamination at the sealed edge. The failure pressure of the three cell cases are 12.8, 13.8, and 13.9 bar.
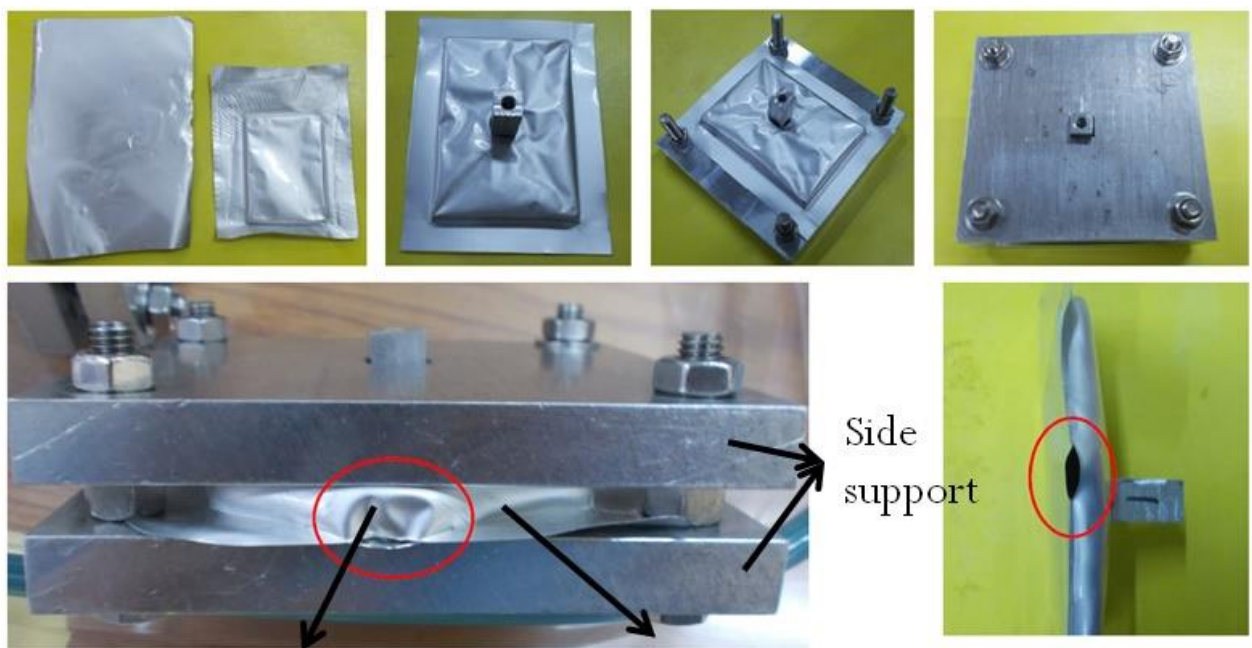

Failure by debonding

Pouch cell

Figure7. Burst test of pouch cell.

\section{CONCLUSIONS}

Experimental characterization (lap shear, t-peel and tensile) of bonded laminate/films are carried out. UTS of laminate is obtained from lap shear and tensile tests. Fracture energy (mode - 1) is obtained from t-peel tests. This is used as input for the cohesive zone model. Structural analysis is carried out for the pouch cell to estimate its pressure capacity.

Tensile strength from lap shear test and tensile test results are close. This indicates robust heat sealing (bond) of pouch cells (cohesive fracture in a lap shear test indicates good process control). 
FEA is carried out for the pouch cells under internal pressure and a sufficient margin exists for the cell at 2 bar. A pressure capacity of 6.4 bar is estimated for the pouch cell in assembly condition. However, the average failure pressure from tests is $13.5 \mathrm{bar}$.

The difference in predicted failure pressure and actual failure pressure is due to the high nonlinear behavior in the test. This could not be captured in the analysis due to non-convergence in finite element solution. Further, few assumptions are made in the CZL used in the finite element model. Christopher's thesis [10] provides insights into the procedure for the extraction of cohesive zone law from peel tests. Tests have to be performed to extract the CZL for a better understanding of the mechanics of laminated interfaces.

\section{Acknowledgment}

Authors would like to acknowledge, GD, SDEG and, DD, STR for constant and continuous encouragement in reviewing this technical paper.

\section{REFERENCES}

[1] Kiehne A. Battery Technology Handbook, 2nd edition,New York: Marcel Dekker, Inc., 2003.

[2] Isidor B. Batteries in a Portable World, 3rd edition,USA: Cadex Electronics, Inc., 2011.

[3] Isidor B. Types of Battery Cells in Battery University,USA: Cadex Electronics, Inc., 2011,

[4] David L. Thomas, B, Reddy. Handbook of Batteries, 3rd edition, New York: McGraw-Hill, ISBN 0-07135978-8, 2002.

[5] Shashank A, Ajay K, Shen W. Application of robust design methodology to battery packs for electric vehicles: identification of critical technical requirements for modular architecture. Batteries 2018; 4(3): 30. doi:10.3390/batteries 4030030

[6] Heydecke J. Introduction to Lithium Polymer Battery Technology. Jauch Quartz GmbH \& Jauch Battery Solutions GmbH, In der Lache 24, 78056 Villingen-Schwenningen, Germany, 2018.

[7] Rivlin RS. The effective work of adhesion. Paint Technology 1944; 9: 215-218.

[8] Kendall K. The adhesion and surface energy of elastic solids. Journal of Physics D: Applied Physics 1971; 4(8):1186.

[9] Alfano G, Crisfield MA. Finite element interface models for the delamination analysis of laminated composites: mechanical and computational issues. International Journal for Numerical methods in Engineering 2001; 50: 1701-1736. https://doi.org/10.1002/nme.93.

[10] Christopher K. Mechanics of peeling: cohesive zone law and stability, PhD Thesis, California Institute of Technology, Pasadena, California, USA, 2011.

[11] Miao T, Tian L, Leng X, Miao Z, Wang J, Xu C, Liu L. A comparative study of cohesive zone models for predicting delamination fracture behaviors of arterial wall. Open Physics 2020; 18: 467-477.

[12] Bonifaz EA. Cohesive zone modeling to predict failure processes. Canadian Journal on Mechanical Sciences \& Engineering 2011; 2(3): 42-54.

[13] Zhang ZZ, Paulino GH. Cohesive zone modeling of dynamic failure in homogeneous and functionally graded materials. International Journal of Plasticity 2005; 21: 1195-1254.

[14] Pany C, Sundaresan MK, Rao BN, Sivasubramonian B, Nair NJ. On the bursting of an HSLA steel rocket motor case during proof pressure testing. Steel Grips (Journal of Steel and related Materials) Application 2012;10: 434-438. 